Trabajos y Comunicaciones, 2da. Época, No 47, e056, enero-junio 2018. ISSN 2346-8971

Universidad Nacional de La Plata.

Facultad de Humanidades y Ciencias de la Educación.

Departamento de Historia

\title{
"Bajo fuerzas de ocupación". Violencia y revolución en Trinchera de la Juventud Peronista (1960-1963)
}

\author{
"Under occupation forces". Violence and revolution in Trinchera \\ de la Juventud Peronista (1960-1963)
}

PALABRAS CLAVE

Derecha

Violencia

Revolución

Juventud Peronista

Sesentas

KEYWORDS

Right

Violence

Revolution

Peronist youth

Sixties

\section{Andrés N. Funes * \\ * Instituto de Altos Estudios Sociales - Universidad Nacional de San Martin, Argentina| andrez zero@hotmail.com}

\section{RESUMEN}

Hablar de "derecha" y/o "izquierda" implica referirse conceptos polémicos; esto es, que producen agrupamientos políticos y simplifican, en este proceso, la heterogénea realidad. En los abordajes historiográficos, su utilización puede conducir a un cercenamiento de las complejidades, matices y tensiones de los fenómenos estudiados. Optando por un análisis que ponga aquellos en primer plano, este trabajo pretende desentrañar el significado que adquirieron la violencia y la revolución en Trinchera de la Juventud Peronista, boletín editado entre 1960 y 1963 por el primer nucleamiento juvenil peronista formalmente organizado pos 55: la "Mesa Ejecutiva de la Juventud Peronista".

\section{ABSTRACT}

Talk about "right" and/or "left" implies referring controversial concepts; this is, they produce political groupings and simplify, in this process, the heterogeneous reality. In historiographic approaches, its use can lead to a reduction of the complexities, nuances and tensions of the phenomena studied. Choosing an analysis to put those in the foreground, this paper seeks to unravel the meaning of violence and revolution in Trinchera de la Juventud Peronista, a bulletin published between 1960 and 1963 by the first formally organized Peronist youth nucleation post 55: "Mesa Ejecutiva de la Juventud Peronista". 


\section{Introducción}

Ninguna revolución ha sido nunca iniciada por las masas (...) ninguna revolución fue nunca resultado de la sedición (...) ninguna revolución es posible allí donde la autoridad del cuerpo político se mantiene intacta.

Hannah Arendt, Sobre la revolución, 1963

Sin embargo, el temor humano ante lo desconocido es, muchas veces, tan grande como su horror ante el vacío, aunque lo nuevo sea superación de ese vacío.

Carl Schmitt, Tierra y mar, 1942

No cabría ninguna duda en calificar al concepto de “derecha/s” y a la distinción "izquierda-derecha” como categorías polémicas, schmittianamente hablando; esto es, su utilización política involucra -incluso aunque ello no sea esgrimido de forma explícita- una distinción entre el campo de los amigos -de pertenencia- respecto al de los enemigos -el que está más allá de este-. 1 Por ello resulta altamente productivo en la lucha política, simplificando la heterogénea realidad y produciendo agrupamientos políticos.

Sin embargo, este concepto se muestra un tanto complejo a la hora de ser usado para emprender análisis

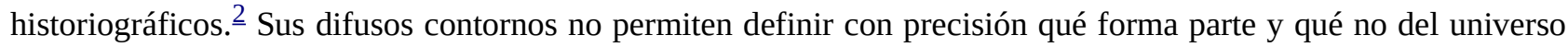
ideológico de la derecha, y cómo esos elementos se encarnan en prácticas políticas concretas, en acciones. Entiéndase bien, no se trata de quitarle importancia al concepto derecha o a la distinción con respecto a la izquierda, sino tan sólo de llamar la atención sobre las dificultades de acercarse a un fenómeno concreto apelando a estas categorías.

Estas dificultades son particularmente evidentes en los estudios sobre las experiencias peronistas de las décadas sesenta y setenta. Muchos trabajos sencillamente apelaron a la etiqueta "derecha peronista" para englobar experiencias que no podían fácilmente ubicarse en el amplio -y, a veces, difuso- espectro denominado "izquierda peronista”. .3 Esa etiqueta podía englobar fenómenos tan disímiles como la Alianza Liberadora Nacionalista, Guardia de Hierro, el Movimiento Nacional Revolucionario Tacuara o el Comando de Organización, la Concertación Nacional Universitaria o la Juventud Sindical Argentina.

En este sentido, podría coincidirse con las reflexiones que al respecto ha hecho Juan Luís Carnagui (2010): en torno a la categoría "derecha peronista" se ha construido una suerte de sentido común, que llevó a obturar los matices y particularidades propios de los fenómenos, en favor de una lisa y llana simplificación de los conflictos políticos. Una manera de salir de este atolladero podría ser renegar de las simplificaciones "derecha o izquierda" peronista para recuperar precisamente esos matices y particularidades obturados. La idea de que los sesenta y setenta presentaron una "nebulosa militante" (Cucchetti, 2010), permite no sólo esto sino también ayuda a comprender las dinámicas y complejas trayectorias de muchos de los militantes peronistas de aquellos años.

Teniendo en mente la compleja y dinámica realidad del peronismo a comienzos de los años sesenta, en este trabajo se pretende interrogar a la "Mesa Ejecutiva de la Juventud Peronista de Capital Federal y Gran Buenos Aires",

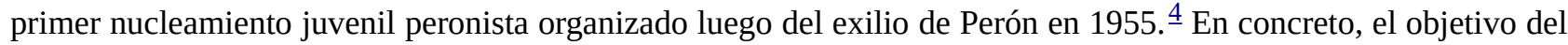
trabajo será analizar la relación que esta organización estableció con la violencia política y la significación que dieron al término revolución. Para el cumplimiento de ambos objetivos, se examinará la publicación insignia de la Mesa, Trinchera de la Juventud Peronista, entre los años 1960 y 1963.

El trabajo está estructurado en tres partes. La primera sirve como una instancia contextualizadora, a los fines de 
comprender algunas de las vicisitudes por las que atravesó el peronismo en los años inmediatamente posteriores al derrocamiento de Perón. En la segunda, se interroga la doble valencia de la violencia en Trinchera: como reacción frente a un estado de cosas vivido como intolerable y, también, como instrumento de lucha. Finalmente, se analiza el doble significado que adquirió la palabra revolución en las páginas de la publicación: un futuro deseado y un pasado frustrado.

\section{El contexto como marco: “desperonización” y CONINTES, sabotajes y “caños”}

El golpe de Estado que derrocó a Juan Domingo Perón el 16 de septiembre de 1955 e instaló tan sólo unos días después al General Eduardo Lonardi como Presidente de la Nación, tomó para con las huestes del exiliado líder una serie de medidas que apuntaban a generar una "desperonización" de la sociedad argentina; un intento "de matar, de borrar del cuerpo social cualquier recuerdo del líder y de su movimiento” (Poderti, 2010; p. 67). Esta tentativa involucró un conjunto de disposiciones que iban desde la remoción de los nombres de Perón y de su esposa de toda calle, plaza o institución que hubiese sido bautizada de ese modo hasta la prohibición de libros peronistas e incluso la de entonar la famosa marcha "Los muchachos peronistas".

Sin lugar a dudas la intentona por "desperonizar" la sociedad adquirió nuevos visos luego del arribo en noviembre del año 55 del General Pedro Eugenio Aramburu a la Presidencia y de la sanción del decreto-ley $4161 \underline{5}$ que decretó la disolución del Partido Peronista y de la Fundación Eva Perón, además de la confiscación de todos sus bienes.

A partir del fallido levantamiento cívico-militar del General Juan José Valle, el 9 de junio de 1956, que el experimento "desperonizador" adquirió sus contornos más violentos. Por un lado, se continuó con el desmantelamiento del aparato peronista, deteniendo a reconocidos ex líderes políticos y dirigentes sindicales peronistas, y purgando, también, a las Fuerzas Armadas. Y por el otro, se buscó responder a las bombas, los sabotajes, los atentados e incendios vinculados a la agitación peronista con toda la fuerza del aparato represivo estatal. Si, por un lado, claramente la caída de Lonardi mostró los estrechos límites de una política conciliadora, la asunción de Aramburu simbolizó el fin de toda ambigüedad con respecto al peronismo.

En los hechos, la “desperonización” fracasó estrepitosamente, tal y como lo demostró, por ejemplo, la elección de constituyentes de junio de $1957^{6}$ para la reforma de la Constitución Nacional. En definitiva, como argumentó Mónica Gordillo en 2003, lo que ese fracaso produjo fue un "refuerzo de la identidad peronista alimentado por discursos y prácticas violentas que llamaban a resistir hasta que se hiciese efectivo” (p. 333) el ansiado regreso de Perón.

La retirada de la Casa Rosada de los militares y la celebración de elecciones nacionales en febrero de 1958, que dio como ganador al candidato de la Unión Cívica Radical Intransigente (UCRI), Arturo Frondizi, estuvo caracterizada por la implementación de los decretos 9880/58, 2628/1960 y 2639/1960, que configuraron los contornos del "Plan CONINTES” (Conmoción Interna del Estado). Bajo este plan, el gobierno de Frondizi dotó a las Fuerzas Armadas del poder para intervenir en los conflictos políticos internos, a los fines de "asegurar el pronto restablecimiento del orden público", como rezaba el primero de los decretos mencionados. El territorio nacional fue dividido en cuatro "Zonas de Defensa", cada una con una autoridad militar responsable, y se subordinaron las policías provinciales a las Fuerzas Armadas y a su Comandante en Jefe, el General Carlos Toranzo Montero.

Como lo muestra Esteban Pontoriero (2015), tras el conflictivo año 59, $\stackrel{7}{\text { la }}$ puesta en vigor del Plan CONINTES en marzo de 1960 resultó ser altamente efectiva; se redujeron considerablemente la cantidad de huelgas $\underline{\underline{8}}$ mediante la intensa represión estatal y la detención de militantes peronistas, que redundó en una notable desmoralización de las bases sindicales más belicosas para con el gobierno de Frondizi y su política económica. Asimismo, entre 1958 y mitad de 1961, disminuyeron drásticamente los "actos terroristas" (bombas y petardos, incendios, sabotajes industriales y al transporte público, ataques individuales, etc.): de 914 registrados para 1958, se pasó a 51 en junio 
de 1961 para todo el territorio nacional (Pontoriero, 2015p. 9).

Ahora bien, ante las apuestas políticas (tan restrictivas como represivas) hacia el peronismo llevadas adelante por los militares de la "Revolución Libertadora” y por el gobierno de Frondizi en los inmediatos años posteriores al desalojo de Perón de la Casa Rosada, podría preguntarse: ¿Cuál fue la actitud que tomaron las huestes peronistas ante estas tentativas? ¿Cómo se adoptaron a las condiciones impuestas por el régimen militar y el radical? ¿Qué tipo de “estructuras” se ensayaron en medio del exilio y de las -en ocasiones- confusas directivas del líder? $\underline{9}$

Ernesto Salas (2014) sostiene que los años posteriores al golpe de Estado de 1955 estuvieron caracterizados por la emergencia, dentro del campo peronista, de los comandos clandestinos y de las estructuras de base de los sindicatos. Los primeros fueron grupos pequeños organizados por dirigentes de segundas o terceras líneas en las zonas urbanas del país, que rápidamente se volcaron a las acciones directas: sabotajes, pintadas, ataques a la propiedad del Estado, por mencionar tan sólo algunas. $\underline{10} \mathrm{Y}$, en lo relativo a las estructuras de base sindical, la intervención de la CGT en 1956, el encarcelamiento de los más renombrados sindicalistas peronistas y la consistente persecución y represión gubernamental hizo que un puñado de nuevos dirigentes fueran ganando peso y se hicieran con la conducción de la mayoría de los gremios industriales del país.

Si bien la convivencia y cooperación entre ambos grupos estuvo dada desde el primer momento, la fallida sublevación militar del General Valle y la recuperación de la mayoría de los sindicatos industriales por los peronistas en 1956-1957, agrietaron ciertamente la relación Los caminos legales abiertos por el régimen militar en el ámbito sindical comenzaron a seducir a esa nueva dirigencia, marchitándose la idea de una inminente insurrección popular. $\underline{11}$

Incluso para los que aún continuaban albergando esperanzas en un levantamiento popular, el fracasado levantamiento militar “properonista” del General Miguel Ángel Iñiguez de noviembre de 1960 significó un punto de inflexión: se abandonó la “esperanza de encontrar militares peronistas dispuestos a combatir”, volcándose sus esfuerzos "hacia la construcción de una fuerza militar autónoma, nacida de los propios grupos” (Raimundo, 1998, p. 220). Desde los sectores juveniles del peronismo, en concreto, de la naciente Juventud Peronista y de su Mesa Ejecutiva $\frac{12}{}$ provino con mayor fuerza este replanteo.

\section{Dos rostros de la violencia. Entre la reacción y su instrumentalización}

A lo largo de los 17 números de Trinchera de la Juventud Peronista, es posible sostener que la violencia adquirió dos significados. Por un lado, una violencia instantánea, pasional y muda, injustificable a priori y producto de la impotencia que un conjunto de actores sintieron hacia un determinado estado de cosas o situación vivida como insoportable (Hilb, 2001a). Arendt (2015) afirmaba que: “[r]ecurrir a la violencia cuando nos vemos confrontados por hechos o condiciones indignantes es enormemente tentador por su inmediatez y rapidez inherentes a aquellas no aquí el punto” (p. 165). Y, por el otro, puede hablarse de un tipo de violencia racionalizada o instrumental, presentada como un medio indispensable e insustituible para alcanzar un determinado fin. Este tipo de acción violenta interviene apelando a la superioridad física, al chantaje y a la coerción; "no hay nada propiamente en ‘común’ para la acción violenta; hay fuerzas en pugna por un objetivo a conquistar” (Hilb, 2001a, p. 4). Mientras la primera de estas modalidades de intervención violenta se arrogaría una rehabilitación de la política tras restituir la balanza de la justicia por sus propias manos, la violencia racionalizada pretendería sustituir a la política, en donde la acción y las palabras dejarían su lugar al choque de fuerzas y a la modelación del espacio común mediante instrumentos (asesinatos, secuestros, etc.).

\section{Reacciones violentas: sangre, sudor y lágrimas}

Para los jóvenes militantes encargados de la redacción del boletín, el periodo abierto con el derrocamiento de Perón en septiembre de 1955 encontró al peronismo, especialmente a sus militantes, sumidos en la persecución, la 
tortura y el hostigamiento permanentes por parte de las fuerzas de seguridad. Esta situación no sólo no se detuvo con el traspaso de mando de las Fuerzas Armadas a Arturo Frondizi en 1958, adquiriendo nuevos visos con el plan CONINTES, sino que constituyó una abierta manifestación de una tendencia ya expresada por el antiperonismo durante los últimos años del gobierno peronista

“[P]ero cuando se encontraron [aquellos que se habían incorporado al peronismo insinceramente] que las banderas la Doctrina Nacional Peronista eran la Independencia, Soberanía y Justicia y no la Prebendas, Tilingadas y Falsasías, comenzaron a conspirar burdamente (28 de septiembre de 1951 - Abril de 1954 - Matanzas en concentraciones peronistas - 16 de junio - Crímenes de lesa humanidad - 16 al 22 de septiembre de 1955 - Atemorización, crímenes y desapariciones” (Trinchera, número 2, p. 1).

"Durante cinco años se nos sometió a la voracidad gorila de todos los enanos de la Revolución Liberticida. Tuvimos sobre nuestras cabezas el /161, los fusilamientos, a Desiderio Fernández, las vejaciones inenarrables de la tortura, hasta llegar al leonino [Carlos] Toranzo Montero” (Trinchera, número 5, p.1).

Estos dos extractos hablan por sí mismos. Los redactores de Trinchera percibían una línea de continuidad entre los frustrados levantamientos militares de 1951 y junio de 1955, el ataque sucedido en una manifestación de la Confederación General del Trabajo (CGT) en el año 54, los fusilamientos luego de la malograda aventura de Valle en 1956, y las persecuciones, torturas y encarcelamientos de los militantes peronistas en los primeros años sesenta.

A su vez, la mención al Jefe de la Policía de la Provincia de Buenos Aires durante la Revolución Libertadora, Coronel Desiderio Fernández, y al Comandante en Jefe del Ejército, General Carlos Toranzo Montero, respondía a una estrategia de explicitación, de denuncia pública, $\underline{13}$ de los enemigos contra los que se combatía desde el boletín (Trinchera, número 9, p. 3).

Un aspecto interesante, relacionado íntimamente con lo expuesto más arriba, lo constituyen la serie de secciones o notas especiales en las que no sólo se dan a conocer los nombres de militantes peronistas encarcelados, heridos o muertos por las fuerzas de seguridad, sino también donde se relatan, con un grado considerable de detalles, las torturas y vejaciones padecidas; una suerte, podría decirse, de “martirología peronista”. Un ejemplo de ello es la descripción de las muertes de José Mario Bevilaqua, Marcelo Medina, Juan Unamuno y Aparicio Suarez $\underline{14}$ o los secuestros, torturas y/o encarcelamientos de Lucia Araoz de Lamadrid, Gustavo Rearte, Juan Carlos Drago, Carlos Alberto Burgos y Orlando Luís Galeano. $\underline{15}$

La martirología peronista, además de funcionar como un modo de legitimación de las acciones violentas, buscó establecer un arquetipo de militante, un modelo de conducta $\underline{16}$ para el joven peronista que se acercaba a la militancia. Se buscaba destacar la capacidad que habían tenido para sacrificar su vida, de "quemar sus años mozos", de "inmolarse por el regreso de Perón” y la reconducción de la "Revolución nacional peronista”, como se verá más adelante. Asimismo, en íntima relación con esta veta sacrificial, estaba el "estoicismo" y la "entereza" con el que asumieron los interrogatorios y las torturas, negándose a “delatar a sus hermanos”.

La denuncia pública hacia los torturadores, las menciones y loas cantadas alrededor de los militantes muertos, encarcelados o torturados, funcionan ambos como instancias justificadoras de la violencia por venir; $\frac{17}{17}$ un tipo de acción violenta no ocurrida y hasta no querida pero que la fuerza de las circunstancias podría dinamizar.

"Entonces, o rectifican su conducta o el Pueblo, determinará el curso de los acontecimientos. Cuando llegue el momento de luchar, el Pueblo luchará junto a su Líder. Y si en la euforia de la lucha algún paredón nos tienta, sólo ustedes serán responsables” (Trinchera, número 9, p. 3). 
“[P]ero lo que no podrá la ley [de proscripción del peronismo] es impedir que esas fuerzas se exterioricen violentamente conquistando el derecho negado y las libertades cercenadas (...) Sólo nos queda el camino de la violencia (...)” (Trinchera, número 10, p. 5).

Funcionando como una suerte de amenaza, en Trinchera se trató de un tipo de práctica de violencia como manifestación instintiva, una erupción rabiosa, frente a un estado de cosas vivido como agobiante. $\underline{18}$ Son precisamente las condiciones legadas por un clima de violencia arraigado los que no sólo dictaminaban la necesidad presente -en esos primeros años sesenta- de explicitar víctimas y victimarios, sino que también de "lavan culpas" a los primeros frente a los arrebatos violentos que pudiesen incurrir en el futuro. En otras palabras, un modo de exponer públicamente a los culpables y exculpar a "quienes buscamos desesperadamente la forma de morir con utilidad en carrera con el tiempo por el retorno inmediato e incondicional de Perón” (Trinchera, número 3, p. 7), interpelados por el arquetipo de héroe-militante construido en el boletín.

\section{Instrumentos de violencia: la amenaza de las armas}

Para Arendt (2015), la violencia instrumental es racional al extremo de alcanzar el fin que podrá justificarla. Y, ya que cuando los hombres actúan nunca pueden conocer certeramente las consecuencias de lo que están emprendiendo, la violencia sólo puede ser racional si persigue objetivos a corto plazo. Teniendo esto en consideración, ¿qué metas pretendían alcanzar los redactores de Trinchera en esta segunda acepción de la violencia? ¿Qué objetivos perseguían con sus llamados insistentes a la lucha? ¿Cuál era el lugar de la militancia juvenil peronista en aquella?

En las páginas de Trinchera primaron las amenazas e intimidaciones públicas, especialmente hacia aquellos cuadros militares acusados de participar en acciones represivas. También fue objeto de amenazas ese complejo constructo denominado "antipatria” u "oligarquía”. Para la Mesa Ejecutiva, mientras el "antipueblo ha festejado con jolgorio y regocijo" un nuevo aniversario del golpe de Estado de 1955, el "pueblo", no olvidando su verdadera naturaleza:

“(...) será inflexible en la hora cercana a la Justicia. Los árboles de Buenos Aires serán pocos para colgar a la oligarquía, sus amanuenses, testaferros e idiotas útiles. Lo haremos sin odio y sin misericordia. Como se extirpa la mala hierba. Para que la paz sea con nosotros por los siglos de los siglos. Amén” (Trinchera, número 12, p. 2).

Este ajusticiamiento, este volver a colocar los platillos de la Justicia en orden, se haría apelando al ahorcamiento, considerando indigna a la víctima (“amanuenses, testaferros e idiotas útiles”) y a la vez exhibiendo dicha muerte como el índice del poder acumulado. A su vez, ¿qué más instrumental y racional que la eliminación física, "sin odios" pero "sin misericordia", de enemigos juzgados como indignos, como si se tratase del desmalezamiento de un jardín (“como se extirpa la mala hierba”)?

Para Trinchera, eran tiempos de lucha. Ni de reconciliación, ni de perdón, ni de encuentro entre viejos adversarios. Era el enfrentamiento entre enemigos, el choque de fuerzas, lo que caracterizaba al presente, explicaban los desaciertos pasados y traerían las mieles del futuro. Esto lo dejaron bastante claro en una editorial titulada "De nuestra carta orgánica": independientemente de que el peronismo constituyera una "doctrina de amor y de justicia”, cuyos fines solo podían concretarse en paz, su desalojo violento del poder en septiembre 1955, "perseguidos sus hombres y sus ideas, maltratados y fusilados, excluidos de la vida cívica, ignorados (...) no existe otro camino para los Peronistas que el camino del sacrificio y de la lucha” (Trinchera, número 5, p.6). Esta era un combate que el peronista no buscaba ni quería pero que aceptaba porque era dictado por la fuerza de las circunstancias; era el propio contexto el que podría dotar a la lucha peronista de contornos violentos. "Frente a una fuerza que utiliza la violencia para reprimir toda exteriorización de una idea, no se puede contestar de otra manera que con la violencia” (Trinchera, número 5, p.6). 
El hecho ineluctable para el peronista que se precie de serlo, entonces, era abrazar la lucha. Esto no sólo involucraba la "lucha por la liberación y el bienestar de todos (...) lucha por implantar definitivamente ese evangelio de paz, de amor y de trabajo" que constituía para ellos la doctrina peronista. Comprendía también una lucha sin cuartel contra todo aquel que pretendiese "hacer una tregua o instalar un gobierno de transacción", al que sólo cabría el degüello, en tanto "es un traidor y merece morir como tal” (Trinchera, número 8, p.4).

Resultaría interesante comparar esto último con el alegato de Frantz Fanon (2009) contra la no violencia, en donde esta era considerada la primera acción tomada por la burguesía tras los estallidos violentos de los colonizados. En otras palabras, la no violencia era aquel "intento por arreglar el problema colonial en torno al tapete verde de una mesa de juego, antes de cualquier gesto irreversible, cualquier efusión de sangre, cualquier acto lamentable” (p. 54). Suplántese "colonial” por "peronismo" y la frase serviría para representar el sentir de una parte de la juventud peronista frente a los intentos neoperonistas $\underline{19}$ y de militares nacionalistas en los primeros años sesenta de presentarse como la solución frente a la "cuestión peronista".

Entonces, si la lucha se presentaba como una cuestión ineludible, una necesidad dictaminada por la coyuntura, desestimándose cualquier tentativa interesada en diluir el conflicto, la Juventud Peronista debía tomar el toro por las astas: transformarse en "una milicia al servicio de la Patria, de Perón y de su Doctrina (...) ser los primeros en el combate, en la lucha o la guerrilla” (Trinchera, número 9, p. 4). En otras palabras, asumir el lugar de vanguardia armada del movimiento peronista para la lucha:

“[c]ontra los traidores a la Patria (civiles y militares) y los arrepentidos 'neos', voceros de la paz (...de la oligarquía); contra las salidas parlamentarias o las formas democráticas; contra los negociadores con el cipayaje y los imperialismos; contra los traidores de todo color" (Trinchera, número3, p. 2).

La Juventud Peronista, a la que Trinchera, en tanto órgano de difusión de la Mesa Ejecutiva de la Juventud Peronista , se arrogaba representar debía ocupar las primeras líneas en la lucha contra las "fuerzas de ocupación”, como insistían en describir a sus antagonistas militares y civiles. Sólo a través de este colocarse en el primer lugar en la lucha podría reconocerse como miembro de legítimo derecho de la juventud peronista; el "olor acre de la pólvora", la "sangre caliente que mana de una herida", la predisposición a empuñar un arma "en defensa de tus ideales” (Trinchera, número 9, p. 4). Todos eran signos a partir de los cuales un joven podía legítimamente reconocerse como miembro de la juventud del movimiento peronista.

\section{Revolución: violencia, ruptura, novedad... y necesidad}

Para incursionar en esos laberínticos y polisémicos significados del término "revolución” y la relación de ésta con la violencia, nuevamente Hannah Arendt ofrece valiosas y fértiles herramientas. En su clásico Sobre la revolución (2012), la renombrada filósofa alemana aseguraba que tanto la revolución como la guerra no podían ser concebidas por fuera del marco de la violencia; ambas estaban determinadas totalmente por la violencia. Este común denominador de la revolución y la guerra que era la violencia, ocasionaba que ambos fenómenos se produjeran al margen de la esfera política, tal y como la entendía Arendt. $\underline{20}$

A su vez, la cuestión de la revolución, así como su relación con la violencia, estaba estrechamente ligada al problema del origen. (Arendt, 2012, p. 25) Justamente la estela "subversiva" de la revolución norteamericana se relacionaba con esa experiencia de sentirse libres, novedad absoluta para las generaciones de hombres que caminaron entre la caída del Imperio Romano y el comienzo de la Edad Moderna; experiencia de sentirse libres para comenzar algo nuevo. Para la filósofa alemana, ni la violencia ni el cambio eran suficientes para describir el fenómeno de la revolución. En todo caso, sólo podía hablarse de revolución cuando el cambio se orientaba a permitir un nuevo origen, donde la violencia era instrumentada para edificar una forma completamente nueva de gobierno $\underline{21}$ y donde el acto de liberación conducía a la constitución de la libertad를 (Arendt, 2012, p. 45). 
Ahora bien, la propia Arendt anotaba que, analizando la historia de las primeras revoluciones, aquellos que las llevaron adelante -léase, que la introdujeron en escena- no fueron en absoluto hombres devotos de la novedad. Allí, en esas primigenias revoluciones, en esos aventureros hombres de acción, aún resonaba aquel significado de "revolución” heredado de las ciencias astronómicas: un movimiento cíclico, rotatorio y sometido a leyes que escapan a la influencia humana, y que no se caracterizaban ni por la novedad ni por la violencia.

Esto llevó a Arendt a reparar en la cuestión de la irresistibilidad, herencia del significado astronómico de la "revolución”, la que en el transcurso del siglo XIX conduciría a la idea de la necesidad histórica. Ambos términos se referían a una suerte de poderosa corriente subterránea, ajena a la voluntad de los hombres y que, con apenas un súbito movimiento, podía arrástralos caprichosamente a los infiernos de la infamia desde el paraíso de las grandes hazañas. Desde el acaecimiento de la Revolución rusa, observaba Arendt, ese encanto mágico de la necesidad histórica se intensificó.

\section{¿Revolución? ¿Qué revolución?}

Las reflexiones legadas por Arendt permiten analizar de qué manera apareció significada la revolución en Trinchera. Se pretenderá mostrar que en la publicación, la revolución fue entendida simultáneamente como un retorno a la truncada experiencia peronista y también como una radicalización de ésta. Por lo tanto, podría decirse que en los jóvenes militares de la Mesa ese significado primigenio de revolución y su resignificación a la luz de las experiencias revolucionarias del siglo XVIII convivieron tensionados.

\section{La siempre diferida pero necesaria "Revolución Peronista"}

"La única salida para la Patria es la Revolución Nacional Peronista” (Trinchera, número 3, p. 10). Esto concluían los miembros de la Mesa Ejecutiva. Ante los crecientes rumores de que las autoridades civiles serían corridas por los mandos militares, desde Trinchera se aseguraba que el deber de la juventud del peronismo era la "preparación para el momento de la lucha” (Trinchera, número 3, p. 10). La revolución aparecía como una necesidad, instancia tan insalvable como inamovible. Por ejemplo, en el número 5, decían que había llegado el momento de que los peronistas se lanzasen a la lucha. Una revolución que aparecía como "innegable necesidad de un Pueblo integrante de una Humanidad oprimida y explotada” (Trinchera, número 9, p. 1).

Esta cuestión de la necesidad y su relación con la revolución como "redención de un pueblo padeciente" recuerda las palabras de Arendt (2012) sobre el "hecho de pobreza": un "estado de constante indigencia y miseria extrema cuya ignominia consiste en su poder deshumanizante (...) [colocando] a los hombres bajo el imperio absoluto de sus cuerpos, esto es, bajo el dictado absoluto de la necesidad.” (p. 79) Estas masas empobrecidas fueron las que, atrapadas por la necesidad, se lanzaron a apoyar la Revolución Francesa. Precisamente, esa introducción en la escena pública supuso privilegiar, en el acto de liberación, las necesidades perentorias por sobre la fundación de la libertad.

Retomando el hilo de Trinchera, a esa revolución no debía entendérsela como una conspiración militar. Se trataba, más bien, de una insurrección, palabra bajo la cual se entendía no sólo un modo de llevar adelante la acción sino también una certeza, una convicción: “sólo a través del levantamiento popular será posible el regreso del General Perón al poder”. Sólo una insurrección popular permitiría "afectar las bases económicas y la estructura política que posibilitan la opresión”. Con el pueblo puesto en primer plano, la revolución partiría, según la publicación, transformando a la Argentina en una "Nación Soberana", para luego "establecer la Justicia Social”; léase, la “dignificación humana, sin más diferencias que las que la naturaleza provea” (Trinchera, número 3, p. 10).

La cuestión era más que clara para Trinchera. Esa afectación de las estructuras económicas y políticas que facilitarían la opresión y que hacían de la Argentina un país dependiente involucraba también, y quizás como condición sine qua non, la "destrucción de la sociedad liberal, corrompida y corruptora, para construir sobre sus ruinas la sociedad justicialista fundada en el amor y el trabajo". Esa transformación sólo sería posible si el 
peronismo -léase, la Juventud Peronista cuya voz la Mesa pretendía representar- tomaba el poder y se imponía "por la fuerza de las ideas y por la fuerza de las armas” (Trinchera, número 12, p. 1).

Únicamente el pueblo era quien podía hacer esa revolución; sólo él “tiene la vitalidad necesaria”, no sólo para arrebatarle "el poder desde el cual la oligarquía" lo somete, sino también la tenacidad para rechazar cualquier posibilidad de participación en el poder que haga a un lado el regreso de Perón. Una propuesta como esta simbolizaba para Trinchera una renuncia a las "banderas del 17 de Octubre" como también a "guardar lealtad a nuestros mártires asesinados y a nuestros héroes torturados”. En otras palabras, "legalidad a cambio de traición" (Trinchera, número 9, p, 1).

De alguna forma, aceptar esta oferta para constituir un "peronismo sin Perón”, $\underline{23}$ no sería otra cosa, para los redactores de Trinchera, que traicionar la "naturaleza revolucionaria del movimiento peronista" (Trinchera, número 10, p. 2). Esta naturaleza, debe decirse, estaba dada por dos factores. En primer término, por la figura de Eva Perón. Ella encarnaba la revolución peronista; era la imagen de aquellas "masas por fin liberadas emergiendo a la vida desde el protofondo hirviente de la Historia” (Trinchera, número 9, p. 13). Simbolizaba, a su vez, el sacudir los cimientos del orden de lo socialmente aceptado. Y luego, la presencia masiva de la juventud daba al peronismo un cariz revolucionario. En este panorama, a la juventud del peronismo le tocaba impedir que aquellos elementos ajenos al espíritu revolucionario tomasen las riendas del movimiento. Si ello sucediera, aseguraban desde la publicación, “nuevamente será postergada nuestra revolución” (Trinchera, número 9, p.8).

Explícitamente aseguraban que no iban a permitirlo, aún si para ello tuviesen que dar su vida. Aquí introducen una cuestión importante: el ascetismo. Respondiendo a las acusaciones de terroristas, certificaban:

\begin{abstract}
"Qué pueden saber de nuestros 20 años negados a la vida cómoda del burgués satisfecho... nuestros 20 años sin otra alegría que el deber cumplido, sin otro esparcimiento que la dura tarea cotidiana. Nuestros 20 años expertos en el dolor y el sacrificio... nuestros 20 años conscientes y lúcidos del sufrimiento y los riesgos que demanda la lucha por la liberación del Pueblo. Nuestros 20 años limpios, puros, honestos y sin 'compromisos'. Qué saben lo que es convertirse en ascetas y guerrilleros para poder llamarse verdaderamente revolucionarios” (Trinchera, número 10, p. 3).
\end{abstract}

La conversión de estos jóvenes en revolucionarios, condición indispensable para llevar adelante la transformación de las estructuras políticas y económicas de dominación, requería negar todo lo que se asociaba a la vida cómoda, a la seguridad. En concreto, eran las experiencias asociadas a la persecución y a la tortura, vivencias que continuamente se aseguraba que padecían los militantes peronistas bajo el CONINTES; el dolor y el sufrimiento afianzaban el camino de estos "ascetas y guerrilleros” en su "lucha por la liberación del Pueblo.” Sin ellas, el anhelo de la revolución naufragaría.

La Juventud Peronista, además de asumir presentarse como una compuerta que impediría el ingreso de aquellos elementos contrarios al regreso de Perón, dispuestos a construir un peronismo sin su máximo líder, tomaba el lugar de una vanguardia; una vanguardia que se ubicaba al frente de la lucha, junto a los trabajadores. $\stackrel{24}{\text { En la }}$ insurrección popular que traería a Perón de regreso, la que transformaría las condiciones económicas y políticas imperantes en la Argentina de principios de los sesenta, imperativa necesidad para las masas sufrientes frente a los embates de los gobiernos pos "Revolución Libertadora”, en esta revolución, entonces, la juventud del peronismo se colocaba a su cabeza. Desechando todas las comodidades asociadas a la vida tranquila, se arrojaban a la lucha. Sólo mediante ella, se reconocían como verdaderos peronistas y polemizaban con aquellos que decían serlo pero que no actuaban en consecuencia; "[s]ólo hay una sola clase de peronistas: los que luchan por la revolución nacional” (Trinchera, número 9, p. 8).

\title{
Retomando la trunca "Revolución Peronista”
}

“El 17 de octubre de 1945 se pone en marcha una Revolución, es decir, un cambio de estructuras” (Trinchera, 
número 9, p. 3). Así definían desde Trinchera el acaecer del peronismo. Las lecturas que sobre el "Día de la Lealtad" hicieron desde la publicación son más que interesantes. Con insistencia se consideraba a ese 17 de octubre del año 45 como el año en que la revolución peronista tuvo su piedra de toque. $\underline{25}$ En un relató bastante rococó sobre la clásica jornada, aseguraban:

"Las masas laboriosas rompieron los esquemas, cambiaron las estructuras, se autodeterminaron. Y fueron generosas... allí se equivocaron. Tembló la oligarquía... pero no la mataron. Retrocedió el gringo... pero quedó esperando. La revolución se hizo cantando y sonriendo... por eso la han frenado. En su propio martirio se está clasificando. Y bañados en la sangre de los que se opongan... seguirá avanzando” (Trinchera, número 12, p. 9).

Este extracto desborda de significados. Por una parte, pareciese como si la sola irrupción de las masas del "17 de Octubre” necesariamente significó un quiebre con el estado de cosas $\underline{26}$ imperante; como si por su sola aparición hubiese agrietado el orden político. Otra forma de decir que la presencia de las masas en la luz pública fue lo que dotó a la jornada de su cariz revolucionario. Por la otra, la revolución que ellas significaron quedó truncada por no cambiar completamente, por no ir al hueso del problema: la dominación oligárquica. En definitiva, el aparecer de las masas no llevó a la completa eliminación de la "oligarquía”, lo que frenó y después interrumpió la revolución. Sin embargo, esa interrupción no significaba bajo ningún punto de vista una liquidación. La revolución peronista seguiría su curso.

El "17 de Octubre” constituyó una revolución, a entender de Trinchera. Ella habría significado un desplazamiento del poder de los partidos a los sindicatos; independientemente que los partidos políticos continuaron vigentes durante el gobierno peronista, estuvieron vaciados de contenido; no eran otra cosa, que simples restos de ese “Estado Liberal Burgués” que la revolución peronista buscó derruir. Las clásicas banderas peronistas de “soberanía política” e "independencia económica” simbolizaban el triunfo de la "Revolución Peronista” frente a los “intentos ‘democráticos’ de oligarcas, cipayos e imperialistas extranjeros” (Trinchera, número 9, p. 4).

Esta cuestión es muy importante para las luchas que desde el boletín y la Mesa se estaban llevando adelante contra aquellos intentos que buscaban utilizar al peronismo y adecuarlo a las estructuras de poder imperantes. Frente a los “cobardes y traidores” la Juventud Peronista debía ser "consciente de su responsabilidad”, lo que significaba estar dispuestos a reemprender la truncada "Revolución Peronista hasta la consumación total de su obra purificadora" (Trinchera, número 5, p. 5). Otra forma de decir, aferrase a las banderas heredadas del "17 de Octubre” y retomar la senda que las masas peronistas trazaron aquella jornada. Empero, para que nunca más pudiera detenerse el curso de la revolución, taparse el surco que ella dejara a su paso, se hacía preciso eliminar todo los elementos considerados como retardatarios.

De alguna manera, este segundo significado de revolución que puede rastrearse en las páginas de Trinchera se relacionaría con esa acepción originaria de revolución que identificó Arendt: revolución como restauración, como un llevar las ruedas de la historia para atrás a aquel punto original desde el que se partió. Por ejemplo, el retorno de Perón desde su exilio, tan ansiado objetivo de la Juventud Peronista, constituía la piedra angular de la continuación de la "Revolución Peronista". Dicho de otra forma: por sí sola, la repatriación de Perón y su ubicación en la cúspide del poder estatal serían los garantes del retomar la “inconclusa” revolución peronista.

Ahora bien, a diferencia de la dependencia que asociaba Arendt de la noción clásica de revolución con un conjunto de leyes inmutables, cíclicas y que escapaban a la voluntad humana, en el caso de Trinchera, la función que se arrogaba la juventud del peronismo era la de transformarse en una herramienta para allanarle el camino a la truncada revolución peronista. Este "preparar el terreno" involucraba tanto la recuperación del legado del "17 de Octubre” como también la eliminación de aquellos sectores que se oponían a ese "volver atrás”. Sólo así, reivindicando la herencia legada por la incursión de las masas peronistas en la escena pública el 17 de octubre del año 45 y suprimiendo a los elementos que desde adentro y fuera del peronismo se oponían, podría producirse ese retorno a los "felices años peronistas". 


\section{Conclusión}

Las páginas precedentes comenzaron poniendo en cuestión la utilización del concepto de "derecha” para emprender análisis historiográficos. Sin menoscabar o censurar la importancia que presenta en lo que a la lucha política se refiere, se buscó subrayar las dificultades que conlleva a la hora de examinar fenómenos concretos.

Estos problemas son particularmente evidentes a la hora de analizar los años sesentas y setentas del peronismo. A raíz de ello, resultó fructífero subrayar la construcción de una suerte de cierto sentido común respecto a la derecha peronista. Como forma de franquear la lisa y llana simplificación de los conflictos políticos a que llevó ese sentido común, y reponer las complejas dinámicas por las que atravesó el peronismo en aquellos años, se prefirió hablar aquí de una "nebulosa militante".

A modo de muestra de esas complejidades, este trabajo buscó examinar los significados que adquirieron la violencia y su relación con revolución en la Mesa Ejecutiva de la Juventud Peronista. Para ello, se interrogó a Trinchera de la Juventud Peronista, órgano de difusión del pensamiento de esta primera organización formal de la juventud del peronismo.

Por un lado, dos fueron las concepciones de violencia encontradas en la publicación. La primera, la reacción violenta, alegaba que el clima de persecuciones, torturas, encarcelamientos y fusilamientos, no sólo dictaminaban la necesidad de explicitar víctimas y victimarios, sino que también hacía imperioso eximir de culpas a aquellas frente a los arrebatos violentos que pudiesen incurrir en el futuro. La otra, la violencia como instrumento, estaba representada por la constante apelación a la lucha contra el régimen en tanto única forma de lograr el regreso de Perón. Sólo mediante ella el militante podía legítimamente reconocerse como integrante de la Juventud Peronista.

Por el otro, también fueron dos los significados que tomó la revolución. La revolución apareció como un futuro posible, un objetivo dictado por la necesidad, que involucraba un cambio de las estructuras de dominación. Mediante la movilización de las masas populares se haría la revolución, en dónde la Juventud Peronista se otorgaba el lugar de vanguardia. Asimismo, la revolución pareció significar además la recuperación de un pasado perdido, ubicado en los primeros del gobierno peronista. Ella inició ese 17 de octubre del año 45, simbolizando un quiebre con el estado de cosas imperante. Pero no se trató una revolución consumada. Fue truncada justamente por no radicalizarse; léase, por no eliminar la "dominación oligárquica”. Nuevamente, la Juventud Peronista se arrogaba el rol de la herramienta para reemprender la revolución.

Entonces, ¿qué vínculo establecieron desde Trinchera entre violencia y revolución? Por una parte, es posible sostener que la reacción violenta se relacionaría con la experiencia de la revolución truncada. Las persecuciones, torturas, encarcelamientos, desmejoras en las condiciones de vida que atestiguaban desde sus páginas se debían al hecho de que la revolución iniciada el 17 de octubre del año 45 no pudo concretarse. Y por la otra, la apelación por la utilización de la violencia como instrumento de la revolución por venir, su razón y necesidad. La eliminación de los enemigos se presentaba como la instancia fundamental en que se allanaba el camino para que la insurrección popular -único modo legítimo de ser de la “revolución nacional peronista”- pudiese florecer.

Por último, dos preguntas puede asaltar inmediatamente: ¿por qué reflexionar sobre la violencia y su relación con la revolución en los primeros años sesenta? Y, derivada a ésta, ¿̇por qué hacerlo apelando para ello a una publicación semi-clandestina y de relativamente poca circulación? Las respuestas son sencillas. De un lado, la cuestión de la violencia política a comienzos de los sesenta ha sido considerablemente obscurecida por los sucesos acaecidos entre finales de los sesenta y comienzos de los setenta, entre el "Cordobazo" y la última dictadura militar. Del otro, la Mesa Ejecutiva y su boletín se muestran sumamente útiles para comprender mejor las transformaciones por las que atravesó la tradición peronista por aquellos turbulentos años sesenta. En cierta forma, la apelación a la violencia, las significaciones que ella tomó y la forma en que se relacionó con la revolución son todos elementos que ayudan a entender mejor esas transformaciones. 


\section{Revista}

Trinchera de la Juventud Peronista, 17 números, octubre de 1960 a junio de 1963

\section{Notas}

1 Para ampliar en la característica polémica de los conceptos políticos, ver Carl Schmitt, 2015.

$\underline{2}$ Empero, numerosos historiadores se abocaron a un riquísimo y sumamente edificante estudio de los fenómenos vinculados a la derecha. Entre la variedad de trabajos que se circunscribieron al ámbito latinoamericano, pueden mencionarse el de Mcgee Deutsch, 2005. Asimismo, para el caso de la Argentina, los de Rock, 1993; Dolkart, 2001; y Lvovich, 2005, por sólo señalar algunos.

3 Entre los más representativos, se encuentran los trabajos periodísticos de Verbitzky, 1986 y González Jansen, 1986, y los académicos de Ladioux, 2005, y Besoky, 2012 y 2016.

4 Si bien los incipientes comienzos de la Juventud Peronista (JP) se dieron entre 1951 y 1953 -como sostiene Acha (2011)- puede afirmarse que la JP se constituyó institucionalmente en 1959, con la conformación de la Mesa Ejecutiva, corolario de una serie de intentos por vincular más estrechamente a los pequeños grupos que actuaban durante los primeros años de la "Revolución Libertadora".

$\underline{5}$ En palabras de Scoufalos (2007), en los redactores del mencionado decreto descolló una mezcla de cierta lucidez y de sobrada ingenuidad. Sí bien fueron lúcidos al reconocer la urgente necesidad de desarticular el imaginario peronista como condición sine qua non para lograr sus objetivos, se mostraron realmente ingenuos al creer que el combate contra el peronismo se resolvería simplemente apelando a la represión, desconociendo los complejos e intrincados mecanismos por los cuales se constituyen y sobreviven las identidades populares.

6 Smulovitz (1991) señala dos cuestiones que complicaron el intento militar por “desperonizar” a las masas populares. En primer lugar, el fracaso en la desarticulación de la identidad peronista, que, aún con la represión y las restricciones legales impuestas, logró mostrar su fuerza, como muy bien las elecciones del año 57 lo señalaron. Y luego, la división de la Unión Cívica Radical (UCR) en enero de 1957 en UCR del Pueblo y UCR Intransigente, con Ricardo Balbín y Arturo Frondizi como hombres fuertes, respectivamente. Las virtuales posibilidades de acceder al poder proscripto el peronismo generaron fuertes rispideces en la UCR, decantando luego en esa escisión.

$\underline{7}$ Luego de una efímera luna de miel con el gobierno de Frondizi, el sindicalismo peronista y la administración radical entraron en una franca confrontación. La crisis crónica en la balanza de pagos obligó al Gobierno Nacional a llevar adelante un implacable plan de estabilización económica a cambio de un desembolso del Fondo Monetario Internacional (FMI). El plan incluía la devaluación del peso, la reducción de tarifas aduaneras, la suspensión de controles de precios e incluso la privatización del frigorífico Lisandro de la Torre. Esto último derivó en la toma de las instalaciones por sus empleados el 15 de enero de 1959 y en la declaración de las "62 Organizaciones” de una huelga general en solidaridad con los trabajadores, terminando en una aguda represión estatal y con la detención de importantes dirigentes sindicales, dos días después. Para ampliar en este sentido, ver: McGuire, 1993 y Salas, 2006.

으 Según James (1990) mientras en 1959 se llegó al pico máximo de diez millones de días perdidos por huelga, para 1960-1961 estos decayeron abruptamente a poco más de un millón, siendo en 1962 apenas 268.000 días perdidos.

9 Aquí no se tratará la retórica que elaboró Perón alrededor de la violencia (las directivas, instrucciones y cartas) en los años inmediatos del exilio por razones de extensión. Para profundizar en este plano, se sugiere: Samuel Amaral, 1993. 
10 Para Raimundo (1998), es posible encontrar comandos fabriles (de composición netamente obrera y que actuaban primordialmente a partir del sabotaje y las huelgas), comandos barriales (dedicados íntegramente a las pintadas, volanteos y enfrentamientos con comandos civiles) e inclusive comandos sumamente heterogéneos, con trabajadores, profesionales liberales y exmilitares en sus filas, embarcados en acciones de sabotaje a medios de transporte público o atentados a edificios gubernamentales.

11 Incluso John William Cooke y el propio Perón, como lo muestran sus intercambios epistolares luego de las elecciones de 1957, comenzaban a percatarse de la fragilidad que envolvía la salida insurreccional.

12 Este boletín de 14 páginas mimeografiadas se editó entre 1960 y 1963. Conformaron su comité de redacción, Envar El Kadri, Héctor Spina, Gustavo Rearte, Jorge Rulli, Felipe Vallese, José María “Tito” Bevilacqua y Alberto Brito Lima, entre otros. Se cree que Beatriz Fortunato fue la responsable máxima de la publicación. Tuvo una salida bastante irregular, producto de las constantes decomisaciones policiales, incluso debido al encarcelamiento de algunos de sus integrantes principales. Resulta difícil establecer con seguridad la cantidad de ediciones por cada número. Puede hablarse de una tirada de 1000 ejemplares, con circulación semi-clandestina. Cada uno de sus números finalizaba con la leyenda "bajo fuerzas de ocupación”, lo que podría explicar que todas sus notas careciesen de firmas (Carman, 2015).

$\underline{13}$ La mención explícita no sólo los llevó a denunciar a represores y torturadores, sino también los condujo a inaugurar una sección especial dentro del boletín, en el cual se detallaban los nombres, apellidos y rangos de aquellos militares involucrados con actos represivos: "Bestias con jinetas”. La particularidad de esta sección, que se introdujo por primera vez en el número 9, fue la de funcionar como modo de denuncia pública y de impugnación hacia las Fuerzas Armadas. Como lo anotaron en ese número inaugural: los torturadores y perseguidores enturbiaron la imagen que tenían de las Fuerzas Armadas, por lo que no podían dejarse engañar; no eran otra cosa más que una "casta de mercenarios que se ampara en el uniforme de la Patria para sojuzgarnos y vendernos al oro internacional”.

14 Respectivamente, aquellas aparecieron en el número 2, p.3; el número 5, pp. 3-5; y el número 17, p. 3.

15 Véase: número 9, p. 5-7; número 3, p. 8; y número 10, p. 13, respectivamente.

16 Asimismo, la invocación constante que tendría la figura de Eva Perón en el boletín apuntaba a inspirar un modelo de conducta para la militancia. Un paradigma de abnegación, fanatismo y renunciamiento personal, bajo cuyo influjo poder llevar adelante la lucha.

17 Para Hilb (2001b), la principal característica de la violencia reactiva está en no presentar una justificación $a$ priori, ya que cualquier tipo de argumento a favor previo desmentiría su inmediatez, racionalizándola y convirtiéndola en un medio para un fin. Pero, ¿de qué forma conceptualizar una prédica por la violencia que no es medio sino una reacción posible a un estado de cosas vivido como agobiante? Una posible respuesta a estos interrogantes es viéndola como una suerte de manifestación de la rabia arendtiana o la violencia reactiva de la que habla Hilb.

18 Slipak (2015), en su análisis de Cristianismo y Revolución, vislumbró algo similar: un planteamiento reactivo de la violencia, que encontraba "su razón de ser en una violencia anterior de sentido contario (...) única respuesta o consecuencia posible a una coyuntura signada por la opresión.” (p. 32) Resultaría interesante preguntarse si, más que una casualidad, no constituyen estos dos ejemplos de concepciones reactivas de la violencia una constante en las publicaciones contestarías de los años sesenta y setenta en la Argentina.

19 "Neoperonismo" fue la designación que tomaron los armados partidarios que algunos dirigentes políticos peronistas edificaron frente al exilio de su líder y la proscripción formal del peronismo. Los neoperonistas, tomando algunas de las banderas clásicas del movimiento proscripto, se propusieron desarrollar un peronismo sin su máximo líder y fundador. Entre los nombres clásicos, pueden mencionarse los de Atilio Bramuglia y su "Unión Popular”, Vicente Saadi y el "Partido Populista”, y Elías Sapag con su "Movimiento Popular Neuquino”. Los 
“neos” serían duramente criticados por las formaciones jóvenes de peronistas que veían en sus actitudes una llana traición a Perón. Para ahondar en los partidos neoperonistas, ver: Arias y Heras, 1993.

$\underline{20} \mathrm{Al}$ margen de la esfera política debido a que ésta, para Arendt, era el ámbito que permitía que los hombres sean capaces de aunar palabra y acción para resolver sus problemas cotidianos. La violencia resultaría ser lo opuesto a la política; un simple medio que precisa justificación, no un fin en sí mismo, como lo era la política. Lógicamente, si la violencia se constituye en el común denominador de la guerra y la revolución, necesariamente se sigue de aquí que éstas acontecerían fuera del espacio de la política. Para ahondar en el concepto arendtiano de política, ver: Arendt, 1997 y Hilb, 2001b.

21 Similarmente, para Lefort (1990) novedad y violencia constituían notas relevantes del fenómeno revolucionario. En "La cuestión de la revolución”, el renombrado filósofo francés aseguraba que: 1) "no se puede disociar la nueva idea de Revolución de la nueva idea del Estado; no se puede disociar la idea de la fundación original del surgimiento de un poder que garantiza a la sociedad su unidad, su identidad (...)” (p. 182); y 2) lo que confería a la revolución su carácter específico es el tipo de sociedad en el que se desarrolla, donde las masas "chocan con el Estado, con un poder garante de la unidad y de la identidad nacionales, y que al oponer la violencia su violencia, niegan su legitimidad y hieren al mismo tiempo al integridad del cuerpo político” (p. 183).

$\underline{22}$ En esta línea, Di Pego (2006) argumenta que en el concepto de revolución en Arendt coexisten la "violencia y la máxima realización de la política (...) [L]a misma violencia, en la medida que implica el final de una forma de gobierno, ha constituido la condición de posibilidad de aparición de la política y de la libertad” (p. 116).

$\underline{23}$ Léase, “neoperonismo”. Ver nota 37.

$\underline{24} \mathrm{Al}$ respecto, ver: Trinchera, número 17, p. 7, y Trinchera, número 5, pp. 3-4.

$\underline{25}$ Resulta interesante reparar en el silencio que se produjo en Trinchera acerca del triunfo electoral peronista del 24 de febrero de 1946 y el comienzo del mandato presidencial de Perón el 4 de junio de ese mismo año”. De alguna manera, es posible concluir similarmente a Slipak respecto al silencio que El Descamisado, revista perteneciente a Montoneros, hizo sobre esas fechas: "desde su perspectiva, poco tenía para decir la legitimidad electoral frente a la legitimidad sustancia originada en el lazo inmediato entre Perón y su pueblo” (2015; 83). Una respuesta tentativa al desestimo en el que incurrió Trinchera se deba quizás a las características que comenzaba a asumir el régimen político pos “Libertadora”: proscripción al peronismo y persecución de sus militantes.

$\underline{26}$ La cuestión sobre el carácter rupturista o continuador del peronismo ha sido objeto de innumerables polémicas intelectuales. Una más que fructífera lectura sobre la revolución dentro del magma discursivo peronista es la que realiza Melo (2009). Su riqueza está en entender que la propia cuestión de la revolución encierra una pluralidad de significaciones que coloca a la respuesta por los orígenes identitarios peronistas en un terreno indecible; ¿Dónde estuvo la ruptura peronista? ¿Fue con la Revolución del 7 de junio del 43? ¿Estuvo dada por las manifestaciones del 17 de octubre del año 45? Ambas y ninguna, totalmente... Precisamente, esa "indefinición” entre total ruptura y total continuidad, su pendular constante, serían el lugar donde el carácter relacional de la identidad peronista, como suerte de síntesis, se manifestaría.

\section{Bibliografía}

Acha, O. (2011). Los muchachos peronistas. Orígenes olvidados de la Juventud Peronista (1945-1955). Buenos Aires: Planeta, Buenos Aires.

Amaral, S. (1993). El avión negro: retórica y práctica de la violencia. En S. Amaral y M. Plotkin (Comp.), Perón: del exilio al poder (pp. 69-94). San Martín: Cántaro. 
Arendt, H. (1997). ¿Qué es la política?. Buenos Aires: Paidós.

Arendt, H. (2012). Sobre la revolución. Madrid: Alianza.

Arendt, H. (2015). Crisis de la república. Buenos Aires: El Cuenco de Plata.

Arias, M. F. y Heras, R. G (1993). Carisma disperso y rebelión: los partidos neoperonistas. S. Amaral y M. Plotkin (Comp.), Perón: del exilio al poder (pp. 95-125). San Martín: Cántaro.

Besoky, J. L. (2012). Leales y ortodoxos, la derecha peronista ¿Una coalición contrarrevolucionaria?. Ponencia en presentada en el 4to Taller de discusión "Las derechas en el cono sur, siglo XX", Buenos Aires, UNTREF.

Besoky, J. L. (2016). “En la patria de Perón, ni judío ni masón”. Aproximaciones a la cultura política de la derecha peronista en los años setenta. Revista de Historia (UNESP), 5 (3), 199-223.

Carman, F. (2015). El poder de la palabra escrita. Revistas y periódicos argentinos (1955-1976). Buenos Aires: Biblioteca Nacional.

Carnagui, J. L. (2010). La construcción de un sentido común sobre la “derecha peronista” en los años ‘70. Antiteses, 3 (6), 1135-1154.

Cucchetti, H. (2010). Combatientes de Perón, herederos de Cristo. Buenos Aires: Prometeo.

Di Pego, A. (2006). Poder, violencia y revolución en los escritos de Hannah Arendt. Nueva Época, 19(52), 101122.

Dolkart, R. (2001). La derecha argentina. Nacionalistas, neoliberales, militares y clericales. Buenos Aires: Ediciones B.

Fanon, F. (2009). Los condenados de la tierra. Buenos Aires: FCE.

González Jansen, I. (1986). La Triple A. Buenos Aires: Contrapunto.

Gordillo, M. (2003) Protesta, rebelión y movilización: de la resistencia a la lucha armada, 1955-1973. En D. James (Dir.), Violencia, proscripción y autoritarismo (1955-19736) (pp. 131-157). Buenos Aires: Sudamericana.

Hilb, C. (2001a). La responsabilidad como legado. El rol de las organizaciones armadas. Revista Puentes, II (5), $1-13$.

Hilb, C. (2001b). Violencia y política en la obra de Hannah Arendt. Sociológica, 16 (74), 11-44.

James, D. (1990). Resistencia e integración. Buenos Aires: Sudamericana.

Ladioux, J. (2005). La mazorca de Perón: prácticas ideológicas de la derecha peronista. Una aproximación a partir de un estudio de caso. Mar del Plata 1970 - 1976”. Ponencia presentada en las X Jornadas Interescuelas, Rosario, UNR.

Lefort, C. (1990). La invención democrática. Buenos Aires: Nueva Visión.

Lvovich, D. (2005). El nacionalismo de derecha. Buenos Aires: Capital Intelectual.

Mcgee Deutsch, S. (2005) Las derechas. Buenos Aires: Universidad Nacional de Quilmes.

McGuire, J. (1993). Perón y los sindicatos: la lucha por el liderazgo peronista En S. Amaral y M. Plotkin (Comp.), Perón: del exilio al poder (pp. 171-217). San Martín: Cántaro.

Melo, J. (2009). Fronteras populistas: populismo, federalismo y peronismo entre 1943 y 1955 (Tesis doctoral inédita) Facultad de Ciencias Sociales, UBA, Buenos Aires.

Poderti, A. (2010). Diccionario del peronismo. Buenos Ares: Biblos. 
Pontoniero, E. (2015). Estado de excepción y contrainsurgencia: el Plan CONINTES y la militarización de la seguridad interna en la Argentina (1958 - 1962). Contenciosa, II (4), 1-16.

Raimundo, M. (1998). La política armada en el peronismo: 1955-1966. Cuadernos del CISH, III (4), $201-231$.

Rock, D. (1993). La Argentina autoritaria. Los nacionalistas, su historia y su influencia en la vida pública.

Buenos Aires: Ariel.

Salas, E. (2006). La resistencia peronista. Buenos Aires: Retórica.

Salas, E. (2014). De resistencia y lucha armada, Buenos Aires: Punto de Encuentro.

Schmitt, C. (2015). El concepto de lo político. Buenos Aires: Struhart \& Cía.

Scoufalos, C. (2007) 1955. Memoria y resistencia. Buenos Aires: Biblos.

Smulovitz, C. (1991). En búsqueda de la fórmula perdida: Argentina, 1955-1966. Desarrollo Económico, 31 (31), 113-124.

Slipak, D. (2015). Las revistas montoneras. Buenos Aires: Siglo XXI.

Spinelli, M. A. (2005). Los vencedores vencidos. El antiperonismo y la Revolución Libertadora. Buenos Aires: Biblos.

Verbitzky, H. (1986). Ezeiza. Buenos Aires: Contrapunto. 